\title{
نظريات الستراتيجية في الجغرافيا السياسية
}

\author{
د. ابراهيم علي كرو \\ مدرس \\ كلية القانون والسياسة، قسم العلاقات الدولية ، جامعة نوروز \\ اقليم كودستان-العراق
}

المثلاصة

الجغرافيا السياسية، هي دراسة الاقليم السياسية على سطح الكرة الارضية وصفاتها ومدى مقدرتها ، ودورها في حفظ السلم والامن الدوليين. وتعد العوامل الجغرافية والتكنولوجية من العوامل الاساسية لقوة الدولة، لذا ظهرت نظريات ستراتيجية في الجغرافية السياسية من قبل المفكرين راتزل ، ماكندر ، ماهان ، وهاوس هوفر ، حول أهمية دراستها و تحليلها وأثرها على صانع القرار السياسي عند صنع

الكلمات الدالة : الجغرافية السياسية ، الدولة ، هاوس هوفر ، ماكندر ، راتزل ، ماهان

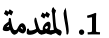

جغرافيته الطبيعية اتعهد لك بان احدد لك تبعا لذلك دوره الذي يؤديه في التاريخ

$$
\text { لابصفة عرضية وانما بصورة دائمة وعلمية وشبه ثابتة)). }
$$

وتعد العوامل الجغرافية احدى العناصر الاساسية لقوة الدولة . فقد اكد المفكر المالماني (عانويل) كانت (( ان الجغرافيا مؤشر رئيسي في احداث التاريخ وان الطبيعة الجغرافية تعطي للسياسة غاياتها بصورة عفوية، وتقود الجنس البشري الى التوسع على الاراضي ونحو انتشار الثقافة)).

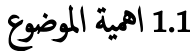

ان النظريات الستراتيجية المكانية والتي هي عنوان بكثنا، سواءكانت البرية ام البحرية ام الجوية من اهم مفردات الجغرافيا السياسية. والعلاقة بين الجغرافيا السياسية وعلم السياسة علاقة ترابطية تكاملية وثيقة كلاهما يدرسان موضوع الوحدات السياسية

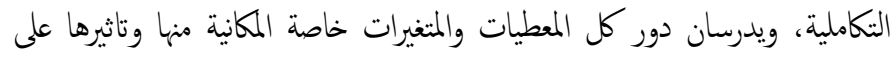
سلوك صانع القرار السياسي سواء فيها يتعلق بالسياسة الخارجية ام الداخلية بشكل

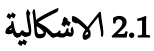
تنطلق من الاسئة الاتية

هل الدول العظمى اعتمدت على هذه النظريات في نزع السيادة العالمية على البر والبحر والجو؟ وفي فرض مناطق النفوذ والسيطرة؟ هل الننائُ كانت واحدة؟ ام سلبية بالنسبة لمن اساء استعمالها واييابية لمن أحسن استعالها. هل النظام الدولي
الجغرافيا السياسية واحدة من الموضوعات الثايكة في دراسات الجغرافيا، وذلك انها تتعلق بربط وتحليل تفاعلات بشرية سريعة الايقاع الاتجاهات السياسية الداخلية والخارجية والاحداث العسكرية مع العوامل الجغرافية الطبيعية الارضية اي المكلية الثابتة. ففي اطار الجغرافيا السياسية فان وحدة التحليل الاساسية هي الدولة. وهي في حد ذاتها ننائُ بشري موقوت الثبات، نتيجة تغيرات سريعة داخلية وخارجية ، وخلال مرحلةحياة الدولة ، طالت ام قصرت. فالدولة قد تكون في اقليم جغرافي واحد او جزء منه او تشمل عدة اقاليم متنوعة. فالجغرافيا السياسية، هي دراسة الاقاليم السياسية على سطح الكرة الارضية وصفاتها ومدى مقدرتها، ودورها في حفظ السلم والامن الدوليين. وكانت النظريات المتعلقة بالجغرافيا السياسية محطة انظار العديد من الباحثين عبر التاريخ فالمؤرخ اليوناني (هيرودوت) ((وجد ان سياسة الدولة تعتمد على جغرافيها، واعتبر حياة المصريين رهينة مياه النيل)). وقال المفكر الفرني فيكتور كوسين اوائل القرن التاسع عشر اذ يقول ((اعطني خريطة بلد ما، طقسه، مياهه، تضاريسه وكل 
والبيئة والاقليم تعني بالدرجة الاولى، التضاريس، المناخ، مصادر الثروة الطبيعة، الموقع، المساحة. - ماحت

في اقليم معبن بالتضاريس نقم طبيعة واشكال توزيع الارض هي اراضي جبلية، ام اراضي سهلية، ام اراضي هضاب، وكذلك الماء ومواضع كل شئ. وكذلك بواسطة الاقليم نعرف على الاهار والبحيرات والمسطحات المائية الاخرى وتاثيراتها على الدولة.

وتحدد نطاق سيادة الدولة بواسطة الحدود المغلق للاقليم. ان فكرة العلاقة بين البيئة، اي الاقليم الجغرافي واساليب الحياة السياسية والاجتاعية قد نوه عنها الكثير من مفكري السياسة في العصور القديمة ، الوسيطة والحديثة ، مثل ارسطو وبودان ومونتسيكو حنى لنراها تبدوا قرية المى مفهوم الحتمية في كنابات المفكر الفرنسي (فيكتور كوسين) اوائل القرن التاسع عشر اذ يقول (( اعطني خريطة بلد ما، طقسه، مناخه، رياحه، وكل جغرافيته الطبيعة، اعطني منتجاته، وموارده الطبيعية، فاتعهد لك في جانبي بان احدد لك تبعا لذلك دوره الذي يؤديه في التاريخ لا بصفة

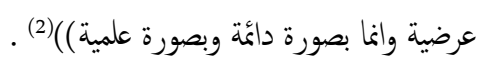

وتعد العوامل الجغرافية احدى العناصر الاساسية لقوة الدولة، فهي نتيجة بمحوع العناصر الاساسية، وما يتفرع منه الارض، السكان، المواصلات، والثروات الطبيعية، والمؤسسات العصرية ونظام سياسي ديمقراطي (3). ويضيفون الى عوامل قوة الدولة العناصر الروحية والمعنوية مثل العقائد والمبادئ، الذي يكسب التأييد الوطني وعطف الراي العام العالمي(4). وهذه العناصر الجغرافية تحدد حجم الدولة وتاثيرها في النظام الدولي، والارض هذا الجانب يتثل بالعامل الجغرافي ومميزاته وقد استند اليه الكثبرين في الماضي ويستند هذا العامل على العديد من العناصر الاخرى لعل أبرزها الموقع الجغرافي ، فهناك تحتل مواقع استراتيجية متميزة

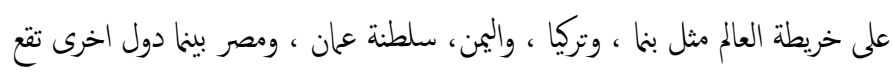
في مناطق معزولة كايسلندا او دولة قارية كالتشاد، وان مواقع الدول تمثل عنصر قوة اساسي في تقييم وزنها بخاصة اذا كانت تسيطر على مرات مائية دولية رئيسة كثناة السويس او باب المندب او البسفور او الدردنيل او مضيق ملقا ، وكذلك ترتبط موقع الدولة بالنسبة للبحار والمحيطات والانهار ، فضلاً عن موقعها على خطوط الطول والعرض.
الجديد الذي يمارس السيطرة والنفوذ تستند على هذه النظريات الاستراتيجية في

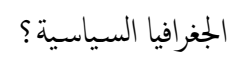
3.1 اعتمدت العديد من الدول على هذه النظريات وكانت النتائُ لبعضها كارثية لأنها اعتمدت كنظريات تبريرية للتوسع والاستعار مثل المانيا واليابان قبل واثناء الحرب العلمية الثانية وكانت ايجابية بالنسبة كلكل من الاتحاد السوفيتي السابق والولايات المتحدة الامريكية وان امريكا تمارس السيطرة والنفوذ استناداً على هذه النظريات لقيادة العالم في النظام العالمي الجديد بعد 1991. 4.1 اعتمد البحث على اكثر من منهج من مناهج البحث العلمي لاسيا المنهج التحليلي والمنهج التاريخي والمقارن في سرد الوقائع وتحليل معطيات ومتغيرات هذه النظريات الاستراتيجية في الجغرافيا السياسية و تاثيرها على السياسة الدولية .

5.1

تم تقسيم البحث الى مقدمة وثلاثة مباحث مسبوقة بمبحث تمهيدي على النحو الاتت: المبحث الهول : القوة البرية ، وتتضمن O اولاً : نظرية المجال الحيوي ل فردريك راتزل O مانياً : ظرية السويداء ل ماكندر

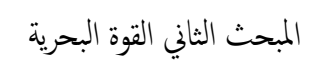$$
\text { O ن ن ن مرية المصير المتوم ل ماهان }
$$$$
\text { المبحث الثالث/ القوة الجوية }
$$$$
\text { O ن ن مفرية سفركي }
$$$$
\text { ثم خاتمة واهم الاستنتاجات }
$$

2. مبحث تمهيدي

\section{2}

يكون الاقليم بالنسبة لعلم السياسة من الاسس المادية للدولة، وللاقليم أثره المباشر على الشعب الذي يعيش فيه وعليه له تاثيرها على الدولة والحكومة وتنظياتها ونشاطانها. 
اولاً : نظرية الجمال الحيوي ل فردريك راتزل

يعد فردريك راتزل ( 1842 - 1904 ) هو مؤسس علم الجغرافيا السياسية إذ قام بنقل بمحل الاراء والافكار الذين سبقوه الى صياغة علمية تحليلة جديدة ظهرت في قواعد محددة من حيث ارتباط الدولة بالعامل الجغرافي ـ من اهم الافكر الهامة التي اوردتها راتزل والذي كان يدرس الجغرافيا في معهد ميوخخ اعتبار الدولة كائن حي ينمو ويتوسع، وان المجال الارضي يمثل قوة سياسية غظمة للدولة. وما انحطاط الدولة وتراجعها الهنتيجة ضعف ادراكها، لاهمية المجال وقد تطور فكرة المجال الجغرافي الى الاراضي لتبلغ الى المجال الحيوي(9). وهي افكلر استعارية توسعية، الهدف منها هو خلق المانيا العظمى التي تسيطر على اوروبا والعالم وابرز افكاره، قانون نمو الدولة، وتوسعها اذا امتلكت رقعة واسعة ، لان ذلك تقوم للدولة مراكز استراتيجية دفاعية وهومية تحمي كيانها، من جهة ومن جهة اخرى تمكنا من القيام بعمليات التوسع عن طريق ضم الدول الاخرى الهيا. كذلك يقدم هذه المساحة للدولة عمقا عسكريا استراتيجيا اقتصاديا يساعد على الانتشار البشري، كل ذلك يؤدي المى زيادة قوة الدولة وهيمته|(10).

وعلى عكس ذلك ان الدولة صغيرة المساحة، تصبح دولة ضعيفة قد يؤدي الى الوضملال والانهيار ، بسبب افتقارها المى ميزات المساحة الكبيرة. مثال ذلك المساحة الكبيرة للاتحاد السوفييتي السابق ( روسيا الاتحادية الان) ساعدت على حاية كيانها من السقوط عدة مرات.على عكس الدول الصغيرة المساحة ، واشار الهيا راتزل ان الكرة الارضية لا تتسع الح لدولة واحدة وهذا يعني ان المانيا يجب وفق اعتقاده ان

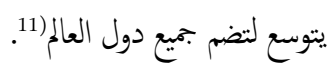
ابرز القوانين التي وردت في ابحاثه و افكاره هي القوانين الذي دعت الى توسيع الدولة

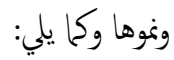
تنمو مساحة الدولة بنمو حضارتها من خلال انتشار لغتها او دياتها ، وهذا الاتتشار الحضاري يعتبر اول مقومات توسع الدول ونموها، فالترابط النفسي والعقائدي بين الوحدات الجغرافية من الممكن ان يكتمل بترابط سياسي، ومن ثخ فان المناطق المتاخمة لمدود دولة يتحدث سكانها بلغتها ، ويعتنقون ديانتها ، من السهل ان يمثلوا امتدادا جغرافيا سهلا في المستقبل الدولة الجار اذا ما رغبت

$$
\text { في النوسع بطرق عسكرية او دبلوماسية(12). }
$$

إذ سادت نظريات في السابق ان هناك ارتباط بين المناخ المعتدل والتقدم وتطور الشعوب والمناخ الحار والتخلف(5.) وهناك دول تمتع بمساحات شاسعة ودول اخرى بمساحات صغيرة، وتشمل اقليم الدولة ما تتنه من موارد مختلفة تحدد قوة الدولة وقدرتها في استخدام هذه الموارد كصادر الطاقة البترول، الفحم، الحديد، الذهب، اليورانيوم، ويشمل اقليم الدولة كذلك ما حول الارض من مياه اقليمة في البحار فضلا عن الاقليم الجوي والمحيطات وامتداداتها، تحت البحر، الجرف القاري. اذن الموارد زائدا قدرة تثثل الاساس المادي للنمو الاقتصادي والتبادل التجاري والقدرة العسكرية في إطار الاقتصاد الدولي. ان النظر في طبيعة المجال الحيوي وفي اهمية السكان والى بعض المميزات والخصائص التاريخية قد بتمكن من تحديد التكوين الجغرافي او هوية ذاتية المنطقة (6). علينا ان ننذك ان مطلق منطقة جغرافية هي المآل الاخير، اختزال واختصار التاريخ قد يستطيع في بعض الاحيان ان يخبرنا الكثير عن الماضي واستشفاف المستقبل (7). تعود الكنابات الاولى للجغرافيا السياسية الى المفكر اليوناني ارسطو، الذي كتب في قوة الدولة المستمدة في توازن ثرواتها مع عدد سكانها، وترك ارسطو افكارا بالغة الاهمية عن وظائف الدولة ومشكلاتها، وظلت افكر ربط المارسات السياسية بالخصائص الجغرافيا، تتطور باسهامات فلسفية، متعاقبة واكتسب قوة بما كتبه بهذا الصدد عبدالرحن ابن خلدون الذي ظهر في مقدمته الثهيرة. حيث شبه ابن خلدون تطور الدولة بالانسان الذي يمر بخمس مراحل حياتية، وهي الميلاد، الصبا، النضج، الشيخوخة، الموت(8). وهذه الدورة الحيانية للدول ونموها وارتباطها بمقدرات الدولة ارضا وسكنا وموارد، كانت ابرز ما نقلنه المفكرون الغربيون، فيما بعد حينا صاغت هذه الافكار الصياغة العلمية، لقيام وسقوط الحضارات وقيام السياسات الخارجية وقوة الدولة ونقوذها وسيادتها العالمية. ومن أبرز هؤلاء المفكرين راتزل، ماكندر، ماهان، هاوس هوفر . واول من تصدى لفكرة المجال الحيوي للدولة بشكل استراتيجي هو العالم الالملني فريدريك راتزل. 3. - المبحث الاول

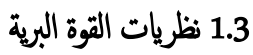

نظراً لأهمية البر وارتباطه بعلم الجغرافيا السياسية والدولة، ظهرت عدة نظريات، منها نظرية المجال الحيوي ونظرية السويداء (قلب الارض) لذا نتطرق اليها من خلال

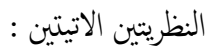


الاستراتيجي دائما يكون على حساب الدول والوحدات السياسية الصغيرة والضعيفة، وهذا ما يمثله الصراع الذي ظهر في العصر الاستعاري إذ تنافس القوى العظىى على ضم ما يفيدها ويثل مصالحها ، فالتنافس بين اسبانيا والبرتغال ، والصراع بين فرنسا وانكلترا ، على ضم المستعمرات ووضعها تحت سلطاتها خير مثال على ذلك ، وما فعلنه المانيا واليابان اثناء الحرب العالمية

\section{الثانية يعد تجسيدا لذلك (17).}

جمحل القول بالنسبة لنظرية المجال الحيوي، وهي توسيع الدولة بمثابة حق طبيعي تفرضه القوانين، التي تحكى في عملية التطور البيولوجي والمادي لمختلف الكائنات الحية على بلى ظهر الارض. ومن هذا المنطلق تم تقديم تبريرات لتسويغ سياسات التوسع الوتليي ان تلك السياسات التوسعية ما هي الا تطبيق لقانون طبيعي وهو ان الضغط السكاني على الحيز المكاني الذي ينتمون اليه يخلق فيهم الحافز الى الصراع من اجل البقاء وذلك على اساس المجال الكبير يجفظ الحياة(18.). مما تقدم يتيين ان هذه النظرية هي نظرية تبريرية استعارية عنصرية غايتها السيطرة على الوحدات السياسية الاخرى دون وجه حق ودون مسوغات قانونية والاستحواذ

$$
\text { على خيراتهم واذلال شعوبهم. }
$$
تقييم نظرية المجال الحيوي ان النظرية العضوية كونها ذات طابع مرن يجب ان تستعمل بحذر كير ذات التشبيه، التمثيل، يجب الا يضغط عله ضغطا شديدا ونستنج منها نتاجُ فوق ما يحتمل ، فن المؤكد انه اذا طبق جميع النواحي فانه سوف يؤدي المى ننائُ غير منطقية ، وكما يلي: تعلم النظرية الحيوية وبحة النظر التاريخية والتطورية في حياة الدول. انها تقتصر على الانار الناتجة عن البيئة الطبيعية والاجتاعية. انها تبرز الاعتاد المتبادل بين المواطنين والمؤسسات السياسية . انها تؤكد الوحدة الجوهرية بين الحياة الاجتاعية والعلاقات المتبادلة المعقدة بين

ان الفرد في الدولة لا يوجد فقط ليسند حياة الكلل، ويعمل على استمراره، فكل فرد مطالب الى حد كير بتشكيل حياته الخاصة وله وعي وارادة خاصة، وان كل هذا لا يصدق على خلايا الكيان العضوي للحيوان (19).
نمو الدولة يكون تاليا لنمو السكان ، مع تزايد اعداد السكان مع تزايد ضغطهم على موارده ومحاولتهم ايجاد مخرج عن طريق الهجرات الى المناطق المجاورة او السفر لرحلات تجارية يؤدي المى زيادة فهم هذه الاقاليم ويخلق نوعا من الالفة بين السكان اي سكان الوقلمين ويساعد ذلك ايضا وجود انهار مشتركة ، او عدم وجود عوائق طبيعية تفصل السكان بين الهقلمين (13). نمو الدولة يتم عن طريق ضم وحدات اصغر او دمجها اذ تزداد هيمنة الدولة ذات القوة الكبيرة وتاثيرها على ما يجاورها من وحدات سياسية اصغر. وتظهر رغبة شديدة من سكان هذه الوحدات الصغيرة في الدخول مع الدول الكبرى المجاورة في تكتلات، اقتصادية او سياسية او عسكرية ـو رأي راتزل ان عملية دمج وتجميع الوحدات السياسية المفتتة وتجميعها في كيان عضوي اكبر يتطلب توالد علاقة قوية بين الروض والساكنين عليها(14). ان حدود اية دولة هي العضو الحي المغلق او المغلق لها وان الحدود لا تعني مدى ضمان سلامة الدولة فحسب بل تعين مدى نموها(15). ان الدولة في نموها تسعى الى امتصاص الاقسام ذات التمة السياسية، وهي الاقسام ذات القيمة الاقتصادية وتكون على شكل سهول او انهار او مناطق ساحلية او مناطق غنية بالثروات الطبيعة والمعدنية او بالبترول او ذات قيمة في انتاج الغذاء. ان تطوير دولة بدائية يتم عن طريق ادخال حضارة متقدمة لدولة اخرى ، وهذا يعني ان تطوير الدول الاخرى لا يتم الا عن طريق سيطرة المانيا عليها ، وكذلك افكلر النمو والوحدة من الدول الكبرى المى الوحدات الصغيرة ذات الجذور الثورية او الذي يبرز فها شخصية قيادية فتبدا هذه الوحدات في قيادة الوحدات الجماورة وضها ، وبداية التوسع وازدياد النفوذ المساحي وهذا ما حدث بالنسبة لتوحيد ايطاليا ، المانيا ، الولايات المتحدة الامريكية ، المملكة العربية السعودية) (16).

تنتشر فكرة الضم واتساع المساحة بصورة سريعة بين الدول ، اذ تؤدي زيادة الثقة السياسية للدول الى تصارع الدول لاثبات الذات، ذلك عن طريق الضم و السيطرة وفرضها نقوذها على غيرها من الوحدات ، و ان هذا الصراع 
وعلى هذا اصبحت المناطق الحاجزة بين الجرمان والسلاف الممتدة من استونيا الى بلغاريا في راي ماكندر مفتاح السيطرة العالمية فهي بذلك مناطق سيطرة مفتوحة لكل من النفوذين الملماني والروسي(26). وان نقطة الارتكاز الجغرافي للتاريخ ضمنها معظم اسس نظريته وقال ان السهول الاوروبية هذا هي التي تشكل منطقة السويداء، واشار ان هذه السهول ،وكذلك منطقة السهول في شرق اسيا تشكل ميدانا للفروسية والتوسع ، ثم وسع مطقة السويداء لتشمل جميع الاقطار الاوروبية من بريطانيا والدنارك الى المناطق السوفيتية (( روسيا حاليا)) وكذلك اسيا الصغرى ، تركيا وهضبة التبت والهند ، واشار ان تحالف المانيا مع روسيا سوف تشكل تهديد عسكري حقيقي على الوجود والكيان

$$
\text { البريطاني. }
$$

وكذلك في حالة سيطرة المانيا على روسيا يشكل خطرا حقيقيا ماحقا لوجود وكيان بريطانيا(27). وحصر منطقة السويداء في المناطق المشار الهيا اعلاه بانها ترتبط بالعالم في منافذ مائية واراضي يابسة، يككنها الانطلاق منها الى جميع انحاء العالم لذلك دعى الى ضرورة تحالف بريطانيا مع روسيا لمنع المانيا من السيطرة على منطقة السويداء. وطور نظرية السويداء بعد الحرب العالمية الثانية، وذلك بتوسيع المساحة الجغرافية لمنطقة السويداء اثر بروز قوة الطيران الحربي الجوي الفعال في الحرب المذكورة ـ اذ قام هذا السلاح بعمليات عسكرية فعالة لمنطقة المحيط المتجمد الشمالي ، واكد على ضرورة انشاء قواعد جوية في المناطق السهولية الداخلية لتستطع الاقلاع منها بدرجة اكثر امنية من قواعد جوية قري السواحل. ان هذا السلاح استطاع ان يدمر اهداف عسكرية لا تستطيع القوات البرية والبحرية ان تصل اليها، لذلك فقد راى انه في حالة تطور السلاح الجوي الى مستوى انشاء قواعد عسكرية فضائية او على القمر سيلقى بدرجة عالية اهمية وفعالية على الصراع البري والبحري. اتجاه هذا الصراع الذي لعب دورا بارزا في الاقسام الشمالية من اوروبا وكندا وسع منطقة السويداء مرة اخرى واصبحت تشمل وفق اعتقاده المساحة الجغرافية الواسعة الممتدة بين شهال شرق كندا والولايات المتحدة الامريكية وشمال اوروبا والمنطقة الاسيوية الروسية والصحراء الافريقية والصحراء العربية وايران وتركيا وهضبة التبت ، وذلك لان هذه المناطق تحتوي على ثروات هائلة معدنية ومزايا سياسية وعسكرية واقتصادية واستراتيجية(28).
ان الكيان العضوي الطبيعي يهلك ويتوقف عن ان يكن مادة حية اذا ما قطعت اعضائه ولكن ليس هذا هو الحال مع الدولة ، عندما يفصل عضو نفسه منها. وهي تعتقد ان الناس بطبيعته كائنات سياسية وان نزوعهم العام ، نو التنظيم الاجتلاعي يخلق الدولة(20). ان الكثير من التشبيهات ، التمثيل بين الدول ككائن عضوي والفرد،ككائن عضوي تشبيهات معبرة الا انها كثيرة ما ثكون بعيدة عن الحقيقة ومتناقضة. ان النظرية العضوية تتعرض الى خطر تمجيد الدولة وتعظيمها كفاية في ذاتها واغفال الحتيقة. في ان غرض وجودها يقوم على رفاهية اعضائها من الافراد او بتعبير اخر تعرض النظرية لخطر التضحية بالفرد من اجل المجتع او الدولة ، كما حدث في حالة الفاثية والنازية(21). ان المفكرين السياسيين من ايام افلاطون حتى الوقت الحاضر قد درجو على ان يقارنوا المجتع والدولة بالكائن العضوي(22). ثانياً :نظرية السويداء( قلب الورض ) لماكندر لقد اعلن الانكليزي ماكندر عن افكاره بشان اثر الجغرافيا السياسية على السياسة لاول مرة في المحاضرة التي القاها في الجمعية الملكية الجغرافية عام 1904 والتي نشرت تحت عنوان ( ( (The Geographical Pivot Of Reality ) عام 1919. والحق ان افكلر ماكندر والذي نحن بصدده بدت متجهة نحو الكشف عن الحقيقة(23). واشار الى اهمة الموقع الذي تشغله روسيا في اوروبا الحديثة ـ فالدولة الروسية اذ قامت في منطقة حدود تنبسط نخو مناطق الاستبس التي كانت طريق الغزوات الكليري من الثرق ، استطاعت ان تتسلط على المجال الاورواسي .(( Heart Land )) وصل ماكندر بملاحظاته الى الغلبة في القوى هي للدول القارية ، لاسيا عندما تحتل موقعا استراتيجيا ومركزيا بهيئ لها التحرك على كل الاتجاهات(24). وانتهى الى فروضه العلمية المشهورة ، والتي مضمونها(25):

$$
\begin{aligned}
& \text { - - من يحكم شرق اوروبا يحكم قلب الارض. } \\
& \text { - - من يحكم قلب الارض يحكم جزيرة العالم. } \\
& \text { - من من ميكم جزيرة العالم يحكم العالم. }
\end{aligned}
$$


تسيطر على معظم بحار العالم ودعا الادارة الامريكية ان تسرع بانشاء الاساطيل المشار الهيا لفرض سيطرتها على محيطات وبحار العالم ولبت الحكومة على هذا الطلب(33).

ولقد سبقوه كناب القرن السابع عشر على مدى اهمية البحار والتحكي بها للتجارة والحرب، ولعل ابلغ ما قيل في تصوير العلاقة بين التفوق التجاري والثفوق السياسي

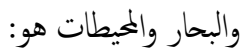
- - " ان من يجكم المحيط يحكم تجارة العالم". - - - " وان من يحكم تجارة العالم يحكم ثروة العالم". - - " وان من يسيطر على ثروة العالم يحكم العالم ذاته "(34).

ومن ثخ فان ميزان القوى مرهون، بميزان التجارة وهي بدورها مرهونة بالتحكي على البحار والمحيطات وهي المصدر الاوحد لقوة الدولة(35). وفعلا قامت الحكومات الامريكية المتعاقبة على السلطة في الولايات المتحدة الامريكية بتلبية هذه الاراء وقامت بتنفيذها وذلك بانشاء العديد من الاساطيل البحرية التي تسيطر على منطقة المصير المحتوم وعلى مناطق استراتيجية بحرية مهمة في جميع اصقاع العالم وكذلك ربط كثير من دول العالم باحلاف عسكرية ، مكنتها من انشاء القواعد العسكرية ، البحرية، في معظم مناطق البحار العالمية والتي تستخدم الان في حاية مصالحها السياسية والاقتصادية كلاستثمرات البترولية والهيمنة على مناطق مخزون هذه الطاقة. وكذلك التحكم في معظم المضايق والطرق البحرية العالمية(36). وقد راى ماهان ان قوة وعظمة بريطانيا هي كانت عبقريتها بالسيطرة على البحار والمواقع البحرية الاستراتيجية المهمة مثل مضيق جبل طارق ، وقبرص، وجزيرة كربت، والخليج العربي ومناطق في الساحل الشرقي الافريقي ، وشمال افريقيا وجزر في المحيط الهندي وعلى الهند ومناطق اخرى كانت نتيجة تفوقها من قواتها البحرية على

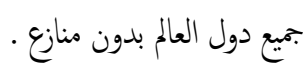
وراى ان البحار التي كانت تسيطر عليها كلما مياه داخلية ضمن اطار الامبراطورية البريطانية ويستدرج من ضرب المثل البريطاني بانه دعى الحكومة الاميركة على انشاء قوات بحرية هائلة وسريعة لفرض سيطرتها على العالم والحلول محل بريطانيا بعد افول نجمها في السيطرة على المراكز البحرية وفعلا تم ذلك حيث استاجرت امريكا بعض
من الواضح ان ماكندر استند في تصويره للمراكز الطبيعية للقوة في العالم الى فرض عام قوامه ان الصراع بين امبراطورية البحر وامبراطورية البر يشكل قانونا ثابتا وان الصدارة في القوة هي لامبراطورية البر (29)، على البحر ومن ثم للدب على الحوت(30). والخلاصة المستوحاة من افكار ماكندر انه اول من استخدم او وضع الجغرافيا في خدمة السياسة والخطط الاستراتيجية والى جانب النظرة العالمية لكوكنا الهرضي وقسم الارض الى مناطق اقلمية كبرى ، قلب الارض ، الهلال الداخلي منطلقا من موقع القلب كنقطة اساسية لتقسيمه اوتليي، واكد تخطيط سياسة امن الدولة على اساس عناصرها الجغرافية(31).

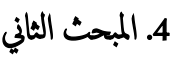
1.4 نظراً لأهمية القوة البحرية على علم الجغرافيا السياسية والدولة واعتقادكل من يسيطر على البحار والمحيطات يسيطر على تجارة العالم ويؤمن الدفاع لشعبه ومن يسيطر على تلى تجارة العالم يسيطر على ثروة العالم ومن يسيطر على ثروة العالم يسيطر على العالم ، لذا نتطرق الى هذه النظرية من خلال نظرية المصير المتوم:

\subsection{4 نظرية المصير المتوم ل (ماهان)}

يعد من ابرز العلماء الامريكيين الذين كتبوا في موضوع القوة البحرية والف في عام 1890 كتابا اسمه " اثر القوة البحرية على التاريخ ، وقد تضمن الكتاب بموعة اراء بهذا الشان ، ومن ابرز ما ورد فيه هو ربطه بين مساحة الارض واستمرارية الدولة. فقد راى ان الدولة التي تكون مساحة قطرها واسعة جدا تكون دولة قوية وذلك لان هذا الاساع المساحي يقدم مزايا للادولة مثل كثة المعادن ووفرة المواد الغذائية واحتمال وجود منافذ مائية تربطه مع العالم ، من الناحية الاقتصادية والعسكرية . أي ان تعاظم القوة البحرية في الولايات المتحدة الامريكية تم عن طريق السيطرة بواسطة الاساطيل البحرية الضخمة على منطقة المصير المتوم وهي المنطقة الجغرافية التي تشمل كندا والبحر الكاريبي والجزء المنتشرة فيها مثل كوبا وهاييتي ، وذلك لان هذه السيطرة على هذه المنطقة تحمي الموانع الامريكية على الساحل الشرقي من النعرض لهجوم بجري اجنبي هذا من جانب، ومن جانب اخر يمكن استخدام المنطقة المذكورة كقاعدة انطلاق للاساطيل البحرية الامريكية(32) ـودعا الى شق قناة بنا ، واحتلال جزر كوام وهاواي في وسط الميط الهادئ، واقامة قواعد بحرية امريكية في الخارج. واعتقد بانه في حالة سيطرتها على المنطقة المذكورة فانها تستطيع مستقبليا ان 
القوات البحرية الفرنسية المتواجدة على ساحل البحر الابيض المتوسط لا يكن التلاحم مع قوتها المماثلة على ساحل الميط الاطلسي الابعد عبورها مضيق جبل طارق التي تسيطر عليه بريطانيا(40). وهذا ما قد يعرقل تلاحم قوتها البحرية المتواجدة على الساحلين، فني حالة دخول فرنسا الحرب مع بريطانيا فلا يككن تحقيق هذا التلاحم. اما موقع اسبانيا فهو ايضا الحسن، لسبب وجود عدة موانئ لها على الساحلين المشرفين على البحر المتوسط والمحيط الاطلسي. وكذلك الموقع الايطلي يسمح لها بالاتصال عسكريا وتجاريا مع كثير من دول العالم اذ يتوفر لها العديد من الموانئ المطلة على البحر المتوسط وكذلك الحال بالنسبة لموقع الولايات المتحدة الامريكية التي تشرف سواحل الاطلسي والميط الهادئ اذ تتصل بالعالم سياسيا واقتصاديا وعسكريا ولكن يعاب عليها انها تجابه اكبر دولتين منافستين لها هـا الاتحاد السوفيتي السابق والصين الشعبية اللتان تشكلان خطرا عليها(41).

ب- السكان: تختلف اهمية السكان ونوعيته من دولة المى اخرى اذا كانت شعب الدولة ، ذو كثافة سكانية ، ويتميز بوجود نوعية ترغب ممارسة الاعمال التجارية والبحرية وكذلك تحبذ الاععال الحربية البحرية مثال ذلك الشعب البريطاني . فان الدولة تستطع ان تنشا قواعد عسكرية بحرية واسعة تستخدما في عمليات لتوسع ومد نفوذها المى مناطق ما ورا ءالبحاركما هي الحال لبريطانيا(42.) وكذلك استطاءت بريطانيا ان تنشأ اساطيل بحرية تجارية ، استخدها في عمليات التبادل التجاري في كثير من قوى العالم ، وعلى عكس من ذلك فاذا كانت شعب الدولة كثير السكان ولكن لا يتميز بوجود نوعية ترغب في الممارسات البحرية والتجارية والعسكرية كالشعب الفرنسي بوصفه شعبا زراعيا اكثر من كونه شعب يرغب في ممارسة الاعمال البحرية لذلك فان هذه الدولة لا تكون

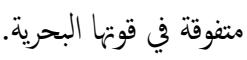
يوجد في بعض الاحيان عدد من الدول التي تكون قليلة لسكن ولا توجد في شعوبها نوعية سكانية في روب البحار بان هذه الدول لا تستطيع ان تنشا قوى بحرية متميزةكا هي الحال بالنسبة لامارات الخليج العربي ، حيث ان هذه الدول على الرغز من وقوعها على سواحل مائية ، وتتوافر لدهيا بعض الموانع ، فانها لا تستطع ان تنشا قوات بحرية عسكرية او تجارية بصورة متفوقة(43).
القواعد العسكرية البحرية البريطانية والسيطرة على هذه اللمواقع الاستراتيجية البحرية. وقال هناك بمموعة من العناصر تؤدي المى تطوير وزيادة القوة البحرية منها:

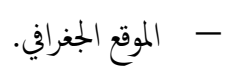

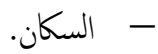
- - خصائص النظام الحكوي. - م- الخصائص القومية والاندماج الاجتماعي في الدولة(37). أ- الموقع الجغرافي: هناك ثلاث مواقع جغرافية تتايز فيا بينها ، قالقوة البحرية للدول تكون متخيزة وفقا لاختلاف موقعها الجغرافي، فهناك الموقع الجغرافي المتميز ، والثاني الحسن ، والثالث السئ السلبي. بالنسبة للموقع الاول المتميز ، لا تحتاج الدولة للدفاع عها اي عن كيانها وضرب مثال على ذلك الموق الجغرافي البريطاني تخيطها البحار من جميع الجهات او الجوانب مما يحميها من التعرض لهجوم خارجي بري ، واضافة الم ذلك فان هذه المواقع قد فتح لها الطرق المائية للتحرك عسكريا واقتصاديا بواسطة اساطيلها مع كثير من دول العالم ولذلك استطاعت بواسطة هذه الاساطيل سابقا ان تنشا الامبراطورية البريطانية، وكذلك الحال اليابان. اما بالنسبة للموقع السلبي، فهي التي تكون لبعض المواقع او جميع حدود قارية اي اراضي يابسة ، اذ تصبح سهلة مثل هذه الحدود لعمليات الغزو البري الاجنبي مثال على ذلك قيام القوات المانية عام 1870 باقتحام الحدود الفرنسية المجاورة لها واقتطاع مقاطعتي الالزاس واللورين من فرنسا وضها الى لى المانيا ، وكذلك قيام المانيا النازية في الحرب العالمية الثانية باقتحام الحدود البرية لهولندا وبلجيكا وضم الدولتين الى المانيا ، وكذلك اقتحام القوات النازية في الحرب المذكورة الحدود السوفيتية البرية واحتلال جزء كير من الاراضي السوفيتية (38). اما بالنسبة للموقع الحسن ، فهو الذي فيه بعض المزايا والعيوب مثال على ذلك الموقع الفرنسي الذي يشرف على الساحل البحر الابيض المتوسط، وساحل المحيط الاطلسي اللذان يربطان فرنسا اقتصاديا وعسكريا مع كثير من دول العالم (39). وقد ساعد ذلك على فرض سيطرتها الاستعارية على الجزائر واجزاء افريقية ، وذلك بسبب وجود موانئ على الساحلين ، ولكن يعاب عليه ان 
وافغانستان في مطلع القرن الواحد والعشرين بواسطة هذه الاساطيل البحرية

الحربية.

اما اذا كان النظام الحكومي لايتسم بالاستقرار السياسي ، لا يمكن لاية حكومة ان تعيش من غير عون شعها وعون الشعب للحكومة دليل على الاستقرار السياسي الداخلي. وكذلك اذا النظام الحكوي لا يتميز برغبة حقيقية توسعية كما هي الحال بالنسبة للنظام الحكوي الهندي، فانه لا يستطيع ان يبني قوى بحرية عسكرية كبيزة (48).

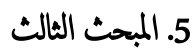

1.5 نظراً لأهمية القوة الجوية على علم الجغرافيا السياسية والدولة والجيش لاختصار الزمان والمكان نتطرق الى أهمية هذه النظرية من خلال النظرية الاتية :

\section{نظرية المصير النهائي ل( سفرسكي)}

برزت القوة الجوية كقوة فاعلة وتفوقت على القوتين البرية والبحرية خلال الحرب العالمية الثانية ،حيث استطاعت هذه القوة وهي الطائرات القتالية ان تصل الى اهداف عسكرية جزت القوى الاخرى الوصول الهيا وذلك لأن هذه الطائرات استطاعت ان تصل الى تلك الاهداف بصورة سريعة، بسبب سرعتها الفائقة وكذلك بسبب نهجها طرقا جوية عبر الدائرة القطبية الشمالية، بجيث مكنها ذلك من تدمير الاهداف المذكورة وابرز من كتب على موضوع القوة الجوية سفرسكي الروسي الاصل والامريكي الجنسية (49)، أكد على الدور البارز الذي لعبته هذه القوة خلال الحرب العالمية الثانية وبسبب فعالية هذه القوات وفي الحربين العالميتين في اجزاء من منطقة

شبه القطبية الشمالية وكذلك في شرق أسيا وكذلك في اجزاء من افريقيا. اما مناطق النفوذ الامريكة المستقبلية فهي تأخذ شكل دائري يشمل اجزاء من منطقة شبه القطبية الشالية ومن اهها شبه جزيرة الاسكا وكندا وكذلك مناطق اخرى متعددة منتشرة حول العالم، وان المناطق التي تتلاق فيها وتمتج مناطق النفوذ السوفيتي والامريكي وتتصادم مصالحها في هذه المناطق اطلق عليها منطقة "المصير النهائي"، وهي المناطق التي اعتقد سفرسكي انه سيقع فهيا تصادم جوي عسكري بين العملاقين السوفييتي والامريكي، وقد اطلق عليها هذه التسمية لأها وفق اعتقاده
ت- الخصائص القومية والثقافية: اذا كان شعب الدولة يشكل قومية واحدة او قوميات مختلفة او ينتي الشعب المى دين واحد، ان تكون هنالك اغلبية دينية واحدة او لغة واحدة او ثقافة واحدة فيكون هنالك تماسك قومي وديني بين افرادها لان اللغة المشتركة والتاريخ المشترك يؤدي الاشتراك الى توحيد عواطفهم السياسية ويذكر هم باسلافهم وامجاده (44). وليست اللغة المشتركة باقل قيمة من التاريخ المشترك بل لعلها اهم لانها ليست وسيلة التفاهم من الحاضر فقط بل هي وسيلة التي انتقل بها تاريخ الاجداد الى كل فرد من افراد الامة في العصر الحاضر. اذن يكون هناك تماسك ديني وقوي بين افراده، اذا كان اغلية الشعب من ثقافة واحدة، ويساعد على تماسك الشعب مع الدولة بصورة اقوى فيترتب على ذلك تزايد فعالية قواها العسكرية

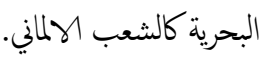
اما اذا حدث الحرب حيث يكون الشعب متميزا بوجود قوميات و اعراق واديان متعددة فان ذلك يؤدي المى التفكك و عدم الترابط بين افراده فيترتب على ذلك عدم التاسك ، تمسك الشعب بصورة قوية مع الدولة .الامر الذي يجعل او يؤدي الم ضعف العلاقة بينها وبالتالي ضعف القوات البحرية للدولة(45)، لان الاختلاف في اللغة والتقاليد من اخطر المشاكل القومية التي تواجه الدول يؤثر عليها الاندماج القوي وعلى العلاقة بين الشعب والحكومة، اذ يتم تخسين ادائها وهذا الاختلاف في التقاليد والعادات يسبب مثاعب للحكومة عند تنفيذ الاصلاحات(46). ث- خصائص النظام الحكوي: تختلف الانظم الحكومية في نوعيها وخصائصها فهناك انواع من الحكومات تتصف برغباتها التوسعية الاستعحرية، تكون لها في بعض الاحيان اهداف ايديولوجية توسعية كما هي الحال بالنسبة للاثار التوسعية الاستعارية الامريكية والسوفيتية السابقة والمانية في عهد هتلر حيث تدفح حكومات هذه الانظمة لتحقيق اهداف توسعية ، وذلك عن طريق استخدام القوى البحرية العسكرية في هذه الاعحال كقيام النظام الحكومي البريطاني والفرني والاسباني اعتبارا من القرن السادس عشر وحتى القرن العشرين وكذلك حالة الولايات المتحدة الامريكية في انشاء الاساطيل البحرية العسكرية لتنفيذ عمليات التوسع ومد النفوذ الاستعاري(47). كما لاحظناها احتلال العراق 
وتقوم الاستراتيجية الامريكية في هذا الموضوع على ركيتين اساسيتين:- ان سلامة الوطن الامريكي وتحقيق الامن القومي للشعب الامريكي، يتواجدان حيث تتواجد المصال الامريكية في كل اصقاع العالم، اي ان حفظ المصاخ الاستقلالية لامريكا سواء كانت اقتصادية ام سياسية او عسكرية او ايديولوجية يساوي سلامة الارض الامريكية والشعب الامريكي، اي انه لا تضمن سلامة الارض الامريكية والشعب الامريكي الا بجفظ المصالح المذكورة. بعبارة اخرى ان الدفاع عن هذه المصالح هو دفاع عن الشعب الامريكي والاراضي الامريكية اي يتساوى اهتمام وحرص الحكومة الامريكية على مصالحها بنفس مستوى اهتمامحا لمحايتها بشعبها واراضيها. - الركيزة الثانية: انشاء العديد من القواعد العسكرية، البرية والجوية، والبحرية، في اماكن عديدة وفي دول وبحار ومحيطات وجزر في العالم. وذلك بعقدها عدد من الاحلاف العسكرية التي اباحت مواثيقها، انشاء هذه الاحلاف وانتشار جنودها في اصقاع العالم والتي مكتنها من بناء القواعد المذكورة ومن ابرز هذه الاحلاف الحلف الاطلسي الذي عقدته مع دول اوربا الغربية وكندا، وبعد ذلك دخلت تركيا فيها في عام 1949، كما عقدت حلفا اخر من عام 1953 مع دول جنوب شرق اسيا والذي اطلق عليه سياتو او حلف مانيلا وكذلك اشتركت فيه ايطاليا وفرنسا.كما عقدت حلفا اخر مع دول امريكا اللاتينية سله حلف ريو واحلاف ثنائية مع اليابان، وكوريا الجنوبية كما اشترك بدور المراقب في حلف بغداد ، والذي اصبح فيا بعد حلف سانتو او المعاهدة المركزية وموجب هذه الاستراتيجية (الاحلاف والقواعد العسكرية الامريكية المنشأة بموجها اصبحت امريكا تطوق عسكريا اكبر دولتين في العالم هما التحاد السوفييتي والصين الشعبية). ولكن بالرغ من ذلك هنالك ثغرات في هذا الططار التطويقي، منها جلاء القوات البريطانية من قاعدة قناة السويس وكذلك خروج العراق من حلف بغداد 1959.وكذلك جلاء قواتها من قاعدتيها العسكريتين من ليبيا والمغرب ولكن استطاعت ان تعوض عن ذلك بانشائها قوة الانتشار السريع في الخليج العربي التي يككن ان تستخدما وقت الضرورة لماية مصالحها في الشرق الاوسط والشرق الادنى وكذلك الان في العراق وافغانستان وشرق الفرات في سوريا ونستنج من ان هذه القوات قد وجدت لحماية المصاح الغربية وليست لماية دول المنطقة ومنع وصول قوة
ستقرر المصير النهائي للعملاقين المذكورين، أي بمعنى العملاق الذي يسيطر عليها ويدحر خصمه سوف ينفرد في السيطرة الكبرى على العالم. وفي تقييم هذه الافكر بخصوص هذه المنطقة نرى بأنه ليس من المحتم ، ان الصدام بينها سيقع في منطقة المصير النهائي بل من المتوقع ان يقع ذلك في مناطق متعددة من العالم خصوصا بعد ابتكار الصواريخ عبر القارات، وابنكار الاسلحة الفضائية، اذ من المتوقع ان يستخدم الفضاء كراكز انطلاق للقوى العسكرية الجوية، واذا تم استخدام ذلك، فان الضربات الجوية لاتوجد فقط في مناطق المصير النهائي، وسوف يحدث في كل المناطق على الكرة الارضية التي تتواجد فيها مراكز وقوى عسكرية لكل منها، هذا من ناحية ومن ناحية اخرى فقد تأثرسفرسكي بالواقع التجريبي للقوى الجوية الذي لعبته خلال الحرب العالمية الثانية، فكانت فكرته متجددا نسبيا، منطقة المصير النهائي الذي مارست فوقها العمليات العسكرية خلال الحرب المذكورة، ولم ينظر بنظرة تطورية الى ما سيحدث من تطورات علمية فضائية بعيدة المدى مككن ان تنقل أهية القوة الجوية من سهاء تلك المنطقة المذكورة المصير الهائي الى اجواء فضائية، ذلك ان العقل البشري لايستطيع اختراع الغيبيات التي لم تحدث بعد . (50) ورأى سفرسكي ان القوة الجوية للدولة والمقومات الوطنية وتشمل عدد من العناصر المتواجدة ضمن اطار الدولة، ومن ابرزها ما تمتلك الدولة من عناصر معدنية وقوى بشرية وتطور تكنولوجي علمي، وكذلك ما يتوافر من عناصر طبيعية كالسواحل والخيطات والبحار والاهار والموانغ.مثلا في حالة توفر سهول وسواحل تمكن الدولة من امكانية انشاء مطارات حربية تؤمن للقوة الجوية قدرة انطلاقية مرنة، والجدير بالذكر بأن القوة الجوية حاليا ومستقبليا وبسبب الابتكارات العلمية الفضائية القائمة فعلا والتي سوف تبتكر مستقبلا سوف تعطي للقوة الجوية اهمية بالغة ودور خطير في التحكم في مصير الحرب، وذلك لان هذه القوة في حالة استخدامها مراكز فضائية سوف تتحكم بكل القوى الاخرى(51).

\section{1الاستناج العملي لاستراتيجية النظريات الثلاث}

اثبتت الولايات المتحدة الامريكية عمليا بأن الاستراتيجيات الثلاث البرية والبحرية والجوية يكن تطبيقها، وان تحقق مجموعة مصالحها المنتشرة في العالم، وبرز الصراع بصورة واضحة بينها وبين ماكان يعرف بالاتحاد السوفييتي، اعتبارا من اخفاق مؤتمر لندن عام 1947، حيث برزت الحرب الباردة بينها واصبحت مراكز النفوذ الامريكي وفق اعثقاد مسؤوليها بأنها محددة من قبل تهديد التوسع الشيوعي السوفييتي. 
السياسية استنادا على علاقة المكان بالسياسة " علاقة القوات البرية ، البحرية، الجوية "حول الاستحواذ على المواقع الاستراتيجية والاقتصادية وعقد المواصلات اللحصول على السيادة العالمية والرفاه الاقتصادي والدولة العظىى.

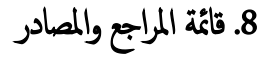

1. د. محمد رضا جليلي وتيري ككليز، جيوسياسية اسيا الوسطى، ترجمة د. علي مقلد، دار الاستقلال للثقافة والعلوم القانونية، ط1، بيروت، 2001.

2. د. هشام آل شاوي، مقدمة في علم السياسة، مطبعة جامعة بغداد، بغداد، 1975.

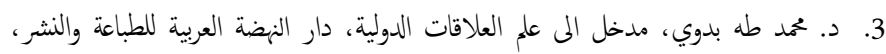

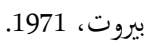

4. د. خليل حسين، الجغرافيا السياسية، دراسة الاقاليم البرية والبحرية والدول واثر النظام العالي الجديد في متغيراتها، دار المنهل، ط1، بيروت، 2007. 5. د. خليل حسين، قضايا دولية معاصرة، دراسة في موضوعات النظام العلي الجديد، دار منهل، ط1، بيروت،

6. د. اساعيل صبري مقاد، نظريات السياسة الدولية - دراسة تحليلية مقارنة، ط1، ويت ،

.1982

7.

الشرق الاوسط، ط2 ، دار النهة العربية للطباعة والنشر، بيروت ، 1979.

8. 2. 9. د. علي عبداله الجباوي، الجغرافيا السياسية والجيوغراسيا، مطبعة جامعة دمشق، ط1، دمشق ، 1989.

10. د. محمد حجازي، دراسة في اسس ومناجج الجغرافيا السياسية ، دار الفكر العربي، بيروت ، التاريخ بلا.

11. د. دولت احمد صادق وآخرون، الجغرافيا السياسية، مكتبة الانكلو المصرية، ط2، القاهرة ، .1963

12. د.براهيم احمد زرقانة ، بعض مشكلات الجغرافيا السياسية، دار النضة العربية، ط2.

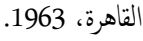

13. د. عبدالعزيز طريخ شرف، الاسس والمشكلات في الجغرافيا السياسية- الاسس العامة، الجزء الاول، مؤسسة الثقافة الجامعية في الاسكندرية، الوسكندرية، 1964. 14. د. بيتز تيلور وآخرون، الجغرافيا السياسية لعالمنا المعاصر - الاقتصاد العالمي - الدولة القومية - الاندماج الاجتاعي، مطبعة السياسة، الكويت، 2002. 15. محاضرات غير منشورة مسحوبة بالرونيو القاه الدكتور خليل الكبيس على طلبة البكالوريس حول الجغرافيا السياسية والجيوبوليتيك، كلية القانون والسياسة، جامعة بغداد للعام الدراسي
هومية معادية الى الاراضي الامريكية وضربها في مناطق تواجدها بعيدا عن الوطن الامريكي وكذلك استخدام قواعدها في ضرب المركز العسكرية المعادية وكذلك ضرب حركات التحرر المعادية للمصاح الامريكية.

ولحفظ الحدود الايديولوجية وحفظ الانظمة الحكومية الموالية للسياسة الامريكية بحيث لاتسمح بقيام حكومات وطنية ذات قرار مستقل ولاتسمح كذلك قيام دول شيوعية. وقرار الحكومة الامريكية في شهر 2018/11 باعطاء فدية كبيرة لمن يدلي بمعلومات عن اماكن تواجد قيادة (ب.ك.ك) الشيوعية خير دليل على قولنا اعلاه .

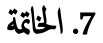
ان الجغرافيا السياسية يتصف بانه علم حديث وهو جزء من الجغرافيا البشرية التي تثناول مدى تفاعل الانسان مع بيئنه. وتعد الجغرافيا السياسية علم الوحدات السياسية من حيث تكوبنها، هيكلها، تطورها في ضوء المعطيات الطبيعية " المساحة ، الحدود ، السواحل ، ، السكان ، الموقع ، الثروات الطبيعية والموارد الاقتصادية ، والتضاريس والمناخ " وهي تلتقي مع علم السياسة لكون كلاهما يدرسان الوحدات السياسية بشكل ترابطي تكاملي وثيق. واتضح ان الجغرافيا السياسية تدرس العوامل الثابتة في الدولة بينما يدرس علم السياسة العوامل المتحركة مثل العوامل الروحية والمعنوية، والعادات والتقاليد والقيم والعقائد والايديولوجيات والنظريات والافكار السياسية مع عناصر الدولة الاخرى. ومازال تتنفظ باهيتها اي الجغرافيا السياسية كفردة قوية من عناصر قوة الدولة وفي الثاثير على سلوك صانع القرار السياسي منطلقا من الحقائق الاتية: ان حقائق الجغرافيا للدولة تفرض على الدولة انماط شبه ثابتة من التفكير في السلوك السياسي لصانغ القرار السياسي في الدولة. ان الحقائق الجغرافيا السياسية للدولة تحدد الواقع السكاني، والاقتصادي والتجاري والعسكري للدولة. ان حجم الدولة وموقعها وثرواتها وسكانها وتضاريسها لها تاثير تمم يفوق على اعتقادنا على بقية المتغيرات في قوة الدولة وفي صنع السياسة الخارجية والداخلية للدولة. فالدولة شاسعة المساحة لها ايجابيات سكانية، اقتصادية ، عسكرية ، تجارية، بينا تتحول هذه الاييابيات الى سلبيات في حالة الدولة الضعيفة مثل السودان إذن مفكري الجغرافيا السياسية الغربيين ادراكا بهذه الحقائق العلمية وضعوا نظريات استراتيجية للجغرافية 
(23) د. محمد طه بدوي، مدخل الى علم العلاقات الدولية، المصدر السابق ، ص126.

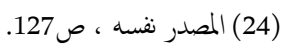

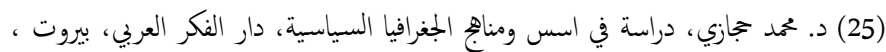

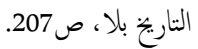

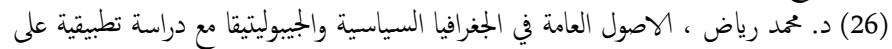

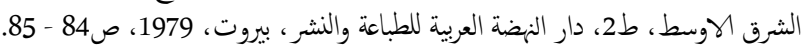

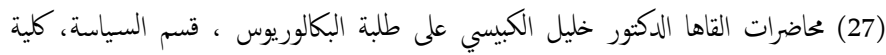

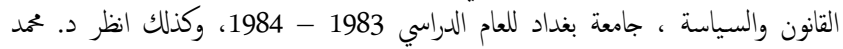
جازي، المصدر السابق ، ص206 - 208.

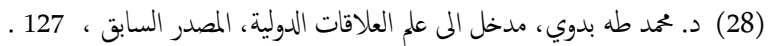

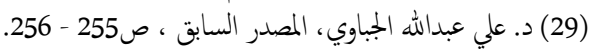

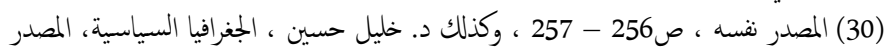

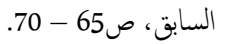

(31) المصدر نفسه ، ص255 ، وكذلك د. محمد حجازي ، المصدر السابق، ص207.

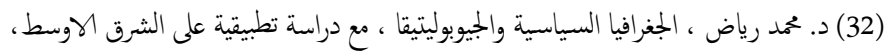

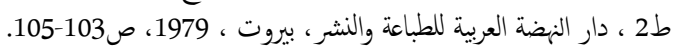

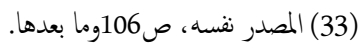

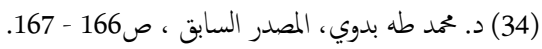

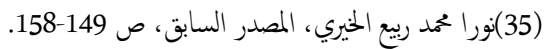

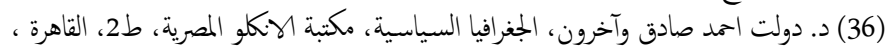

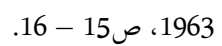

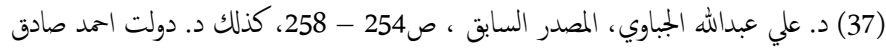

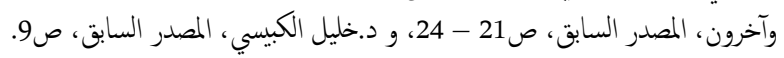

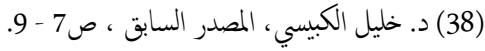

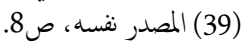

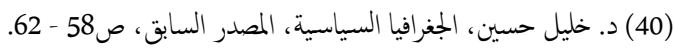

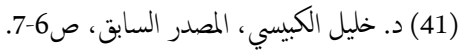

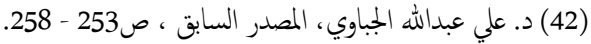

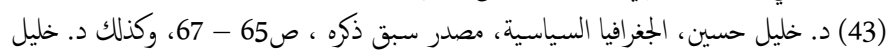

$$
\text { الكبيسي، المصدر السابق ، ص } 8 \text { - } 8 \text { - } 10 .
$$

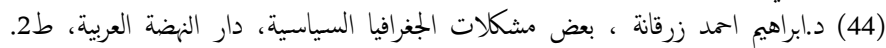

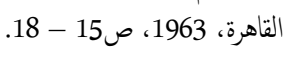

(45) (45) المصدر نفسه، ص15)

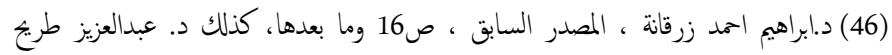

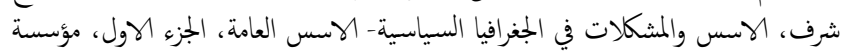

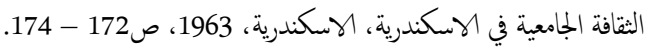

$$
\text { (47) المصدر نفسه ، ص15 - } 16 \text { (48) }
$$

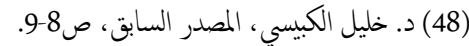

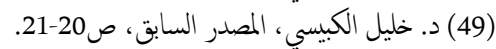

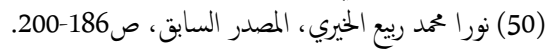

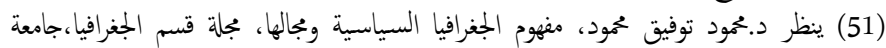

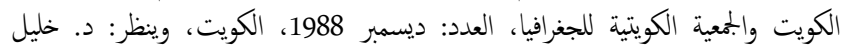

$$
\text { الكبيسي، المصدر السابق ، ص22. }
$$

16. محاضرات غير منشورة القاه الدكتور رامز عمار على طلبة الدكتوراه ، السنة التحضيرية ، كلية

$$
\text { الحقوق والعلوم السياسية، جامعة بيروت العربية، للعام الدراسي } 2011 \text { - } 2012 .
$$

17. د. صدقي يميى فاضل، القوة الناعمة على الشبكة العالمية سww.google.com

18. د.محمود توفيق محمود، مفهوم الجغرافيا السياسية ومجالها، مجلة قسم الجغرافيا،جامعة الكويت

$$
\text { والجمعية الكويتية للجغرافيا، العدد :ديسمبر 1988، الكويت. }
$$

19. نورا محمد ربيع الخيري، مبادئ الجيوبوليتيك، ط1، دار مكتبة عدنان، بغداد،2014.

20. د.زينب عباس موسى، مفهوم الجغرافيا السياسية، شبكة جامعة بابل متاح على الموقع www.uobabylon.edu.iq

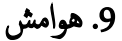

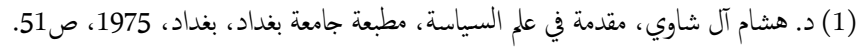

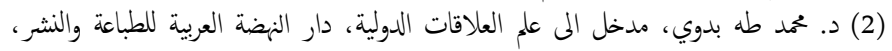

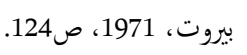

(3) د. خليل حسين، قضايا دولية معاصرة، دراسة في موضوعات النظام العالمي الجديد، دار منهل،

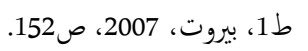

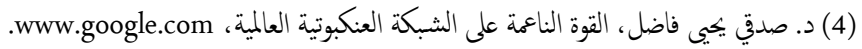
(5) د. خليل حسين، الجغرافيا السياسية، دراسة الاقاليم البرية والبحرية والدولة واثر النية النظام العالمية الميلي

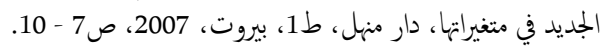

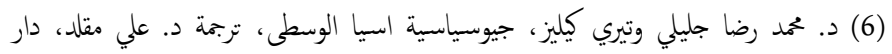

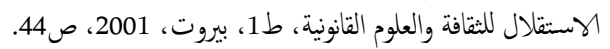

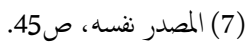

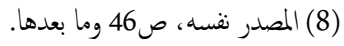

(9) محاضرات غير منشورة القته د. رامز عمار حول الجغرافيا السياسية على طلبة الدكتوراه، كلية

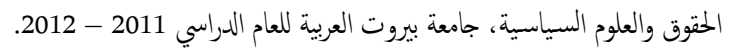

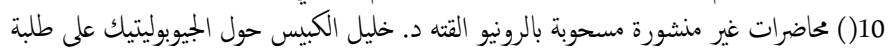

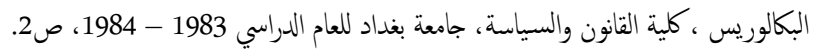

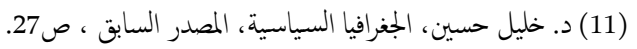

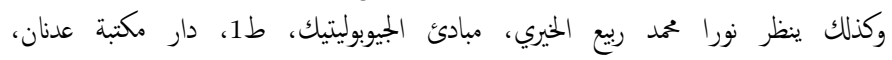
بغداد،2014،ص نو 165-185.

$$
\begin{aligned}
& \text { 1) د. خليل حسين، الجغرافيا السياسية، المصدر السابق ، ص27 - } 28 .
\end{aligned}
$$

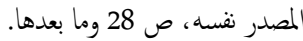

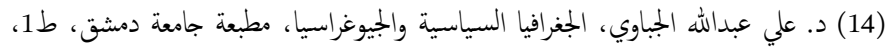

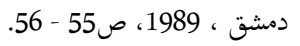

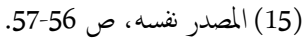

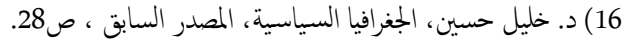

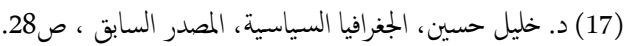

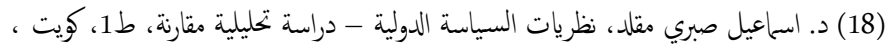

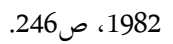

(19) د. محمد عبدالمعز نصر، في النظريات والنظم السياسية، دار النهضة، بيروت ، 1973،

(20) المصدر نفسه، ص31.

(21) المصدر نفسه ، ص34 - 37 - 31 (22)

(22) المصدر نفسه ، ص29. 